Check for updates

Cite this: RSC Adv., 2017, 7, 23494

\title{
A PEO-based gel polymer electrolyte for lithium ion batteries $\dagger$
}

\author{
Wangyu Li, Ying Pang, Jingyuan Liu, Guanghui Liu, Yonggang Wang \\ and Yongyao Xia (DD*
}

A lithium-ion conducting gel polymer electrolyte (GPE) membrane containing PEO as a polymer host and liquid electrolyte has been prepared by a simple one-step procedure. The prepared electrolyte membrane exhibits a good ionic conductivity of $3.3 \times 10^{-3} \mathrm{~S} \mathrm{~cm}^{-1}$ and high lithium transference number of 0.76 at room temperature. Meanwhile, the gel polymer electrolyte membrane shows very good thermal stability. A Li/GPE/LiFeO 4 cell was fabricated to demonstrate the electrochemical performance of the GPE. The cell exhibits good cycling stability with a high capacity retention of $81 \%$ after 500 cycles and as good a rate performance as $\mathrm{LiFeO}_{4}$ tested in liquid electrolyte.

Received 2nd March 2017

Accepted 14th April 2017

DOI: 10.1039/c7ra02603j

rsc.li/rsc-advances

in recent years as a compromise by possessing the advantages of both solid and liquid electrolytes. ${ }^{24-26} \mathrm{Gel}$ polymer electrolyte is a hybrid system formed by trapping a large amount of liquid electrolyte a lithium ion conducting organic solution in a polymer matrix (e.g. poly(ethylene oxide) (PEO), poly (vinylidene difluoride) (PVdF), polyvinyl chloride (PVC), poly (methyl methacrylate) (PMMA) and poly-(vinylidene fluoridehexafluoropropylene) (P(VDF-HFP)) copolymer) through physical and chemical methods. ${ }^{27-32}$ For gel polymer electrolyte, the transfer of lithium-ion mainly depends on the swollen gelled phase or the absorbed liquid electrolyte. By sharing both the beneficial characteristics of solid and liquid electrolyte, gel polymer electrolyte system has advantages of high ionic conductivity, good mechanical strength, better flexibility, wide electrochemical window, good compatibility with electrodes, and an improved trapping capability of liquid electrolytes than conventional separators. In addition, the better thermal stability of the GPE will lead to the improved safety of the lithium ion batteries, ${ }^{33}$ and the encapsulated liquid electrolyte in a solid polymer host can lead to enhanced electrode/electrolyte interface stability toward both electrodes. ${ }^{34}$

Normally, the most common preparation methods for the gel polymer involves the preparation of a porous membrane first and then absorb some of the liquid electrolyte. ${ }^{35-37}$ But the preparation process is a little too difficult to be scaled up for industry use. So an easier synthesis method is needed.

Here, an in situ polymerization method was adopted as a simpler method. PEO was chosen as the polymer matrix which has been studied for decades. ${ }^{38-40}$ Commercialized lithium (hexafluoro) phosphate $\left(\mathrm{LiPF}_{6}\right)$ based liquid electrolytes are used as gelling agents. Trimethylolpropane ethoxylate triacrylate was added as the ionomer. After the treatment of UV light, trimethylolpropane ethoxylate triacrylate was polymerized

Department of Chemistry, Shanghai Key Laboratory of Molecular Catalysis and Innovative Materials, Institute of New Energy, Fudan University, Shanghai, 200433, China.E-mail: yyxia@fudan.edu.cn

$\dagger$ Electronic supplementary information (ESI) available. See DOI: 10.1039/c7ra02603j 


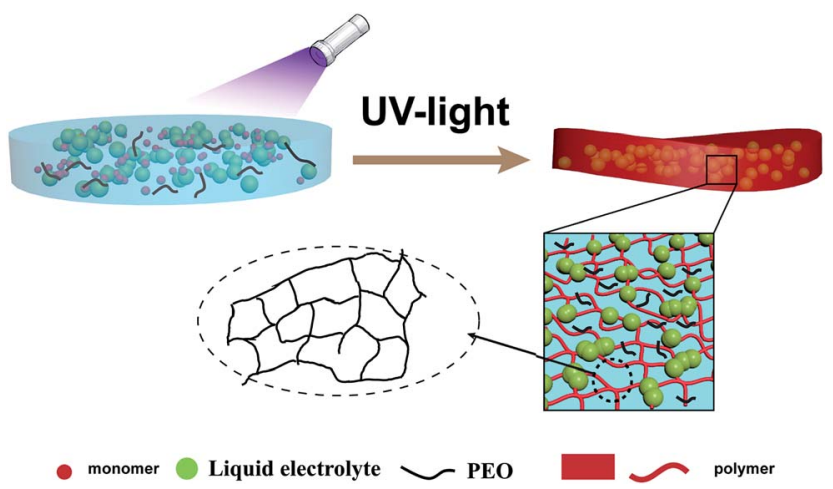

Scheme 1 The preparation process and the illustration of the GPE membrane.

and liquid electrolyte were confined into the solidified framework of the polymer (Scheme 1). The electrochemical properties of the as-prepared gel polymer electrolyte have been evaluated by the study of its ionic conductivity, lithium ion transference number and the electrochemical stabilities against lithium metal. The thermal stability of the GPE has also been tested and compared with commercialized separator saturated with liquid electrolyte. The electrochemical performance of the GPE was tested by measuring the electrochemical properties of solid state $\mathrm{Li} / \mathrm{GPE} / \mathrm{LiFePO}_{4}$ battery which is fabricated with the gelled polymer as electrolyte and separator at the same time and commercialized $\mathrm{LiFePO}_{4}$ as cathode material.

\section{Experimental section}

\subsection{Preparation of gel electrolyte}

Polyethylene oxide (PEO) $\left(M_{\mathrm{w}}=60000\right)$ and LB303 were mixed together to form a solution A. 2-Hydroxy-2-methyl-1-phenyl-1propanone $(0.01 \mathrm{~g})$ was added to trimethylolpropane ethoxylate triacrylate $(3 \mathrm{~g})$ to form solution $\mathrm{B}$. The two kinds of solution were mixed together to form the precursor. Then the precursor solution was poured in to the PTFE plate and exposed to UV irradiation (wavelength of $365 \mathrm{~nm}$ ) for $\sim 10 \mathrm{~s}$. A solidified and flexible gel electrolyte was obtained. All samples were processed and prepared in an argon-filled glove box.

\subsection{Characterization of gel polymer electrolyte}

Thermal gravimetric analysis (TGA) was performed by using a Q20 analyzer manufactured by TA instruments. The experiments were conducted under $\mathrm{N}_{2}$ atmosphere from $0{ }^{\circ} \mathrm{C}$ to $400{ }^{\circ} \mathrm{C}$ at a heating rate of $5{ }^{\circ} \mathrm{C} \mathrm{min}^{-1}$. Differential Scanning Calorimetry (DSC) scans were performed using a DSC 200F3 instrument (NETZSCH, Germany) with a scanning rate of $5{ }^{\circ} \mathrm{C}$ $\min ^{-1}$ under continuous nitrogen purge $\left(50 \mathrm{~mL} \mathrm{~min}^{-1}\right)$.

The ionic conductivity $(\sigma)$ of electrolyte membrane was measured by means of electrochemical impedance spectroscopy (EIS) on Autolab. The electrolyte membrane was cut into round disk and sandwiched between two stainless steels,

$$
\sigma=\frac{l}{R_{\mathrm{b}} S}
$$
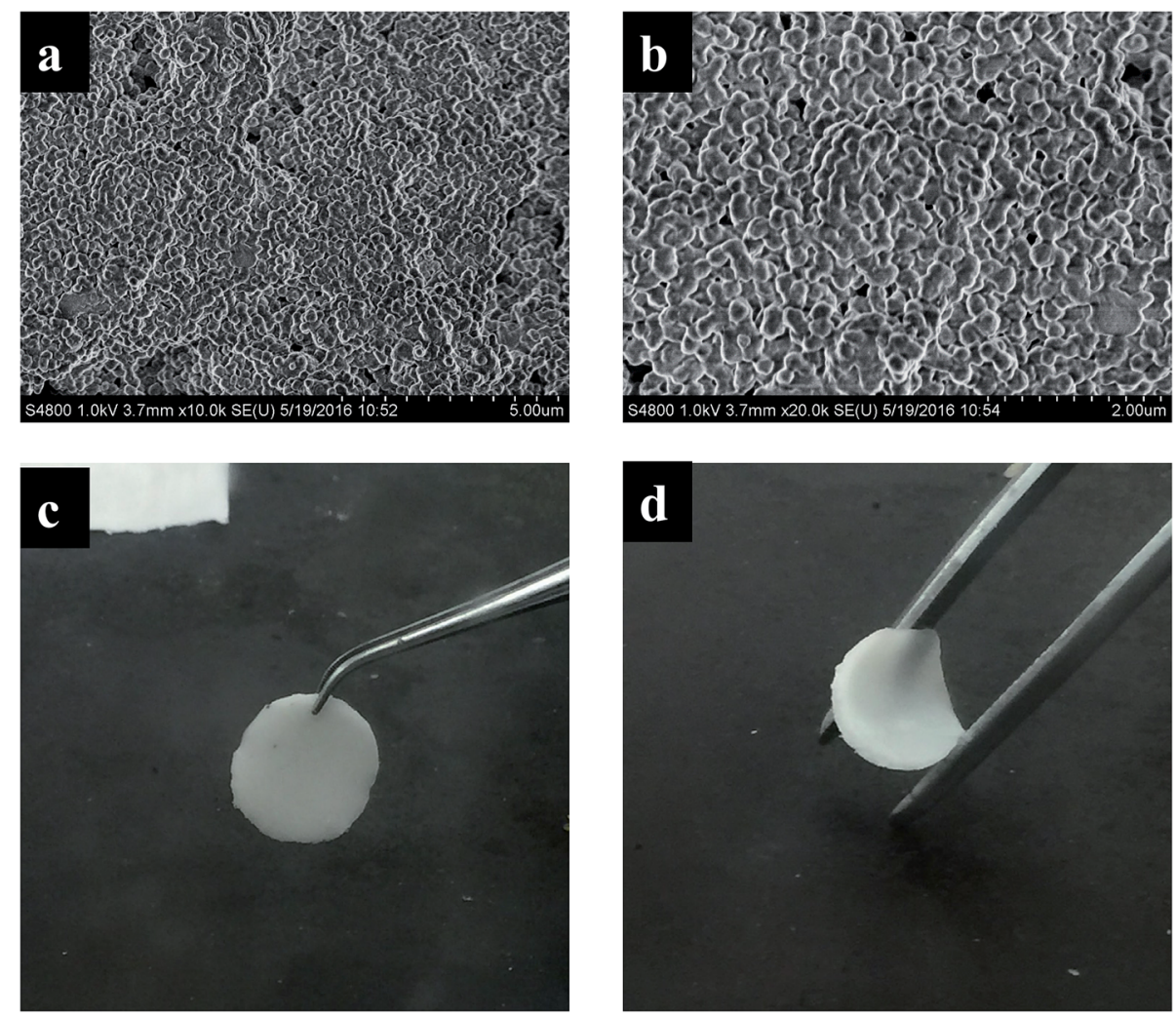

Fig. 1 SEM images ( $a$ and b) and photograph ( $c$ and $d$ ) of the prepared gel polymer electrolyte. 
where $l, R$ and $A$ correspond to the thickness, resistance, and area of gel electrolyte, respectively. Electrochemical impedance spectroscopy (EIS) was measured with potential amplitude of $10 \mathrm{mV}$ and frequencies from $100 \mathrm{kHz}$ to $1 \mathrm{~Hz}$ at various temperatures on electrochemical instrument (Metrohm Autolab PGSTAT302N, AMTECT Company). Electrochemical stability window of the gel polymer electrolytes was measured by linear sweep voltammetry (LSV) obtained with stainless-steel as the working electrode and a lithium foil as the counter and reference electrodes on electrochemical workstation (Princeton Applied Research, AMTECT Company). The measurements were performed between 0 and $6.0 \mathrm{~V}\left(v s . \mathrm{Li}^{+} / \mathrm{Li}\right)$ at a scan rate of $0.5 \mathrm{mV} \mathrm{s}^{-1}$. The lithium ion transference number $\left(t_{\mathrm{Li}^{+}}\right)$was derived by chronoamperometry method and calculated from the Vincent-Evans equation:

$$
t_{+}=\frac{I_{\mathrm{s}}\left(\Delta V-I_{0} R_{0}\right)}{I_{0}\left(\Delta V-I_{\mathrm{s}} R_{\mathrm{s}}\right)}
$$

where, $I_{0}$ and $I_{\mathrm{s}}$ are the initial and steady-state currents, $\Delta V$ is the potential applied across the cell, and $R_{0}$ and $R_{\mathrm{s}}$ are the initial and steady-state interfacial resistances of the passivation layers on the Li electrode.

\subsection{Cell assembly and electrochemical measurements}

The electrochemical property of gel polymer electrolyte was determined with the CR2016 coin cell. The cathode material was composed of $\mathrm{LiFePO}_{4}$, Super-P and PVDF by weighed ratio in $8: 1: 1$. The Lithium metal was used as the anode. All cells were assembled in an argon-filled glove box. The gel polymer electrolyte was hired as both the electrolyte and membrane. The charge-discharge performance and rate capability and cyclic property were tested on LAND CT2001A Battery Cycler (Wuhan, China). The charge/discharge tests were performed in the voltage range of $2.8-4.0 \mathrm{~V}$ at different current densities $(1 \mathrm{C}=$ $160 \mathrm{~mA} \mathrm{~g}^{-1}$ ) at room temperature in a battery testing system (Land Instruments).

\section{Results and discussion}

Fig. 1 shows photograph and the scanning electron microscopy (SEM) images of the prepared GPE. From the photograph it can be seen, the gel polymer electrolyte is a white membrane and is flexible which will be useful for designing wearable or other kinds of electrical devices. The SEM images show the GPE membrane formed a uniform structure which is favorable for

Table 1 Ionic conductivity and exothermic heat of different compositions of GPE

\begin{tabular}{llll}
\hline Number & $\eta / \%$ & $\sigma / \mathrm{mS} \mathrm{cm}^{-1}$ & Exothermic heat/J g \\
\hline 0 & 71.4 & 3.3 & 498 \\
1 & 72.7 & 3.6 & 595 \\
2 & 73.4 & 3.9 & 620 \\
3 & 57.1 & 1.5 & 632
\end{tabular}

lithium ion transference. The IR spectra and XRD of the gel polymer electrolyte was also tested and shown in Fig. S1. $\dagger$

The weight content of the liquid electrolyte of the prepared GPE is $71.4 \%$. For comparison, gel polymer electrolyte of different liquid content is synthesized (see ESI $\dagger$ ) and the influence on ionic conductivity is shown in Table 1. From the
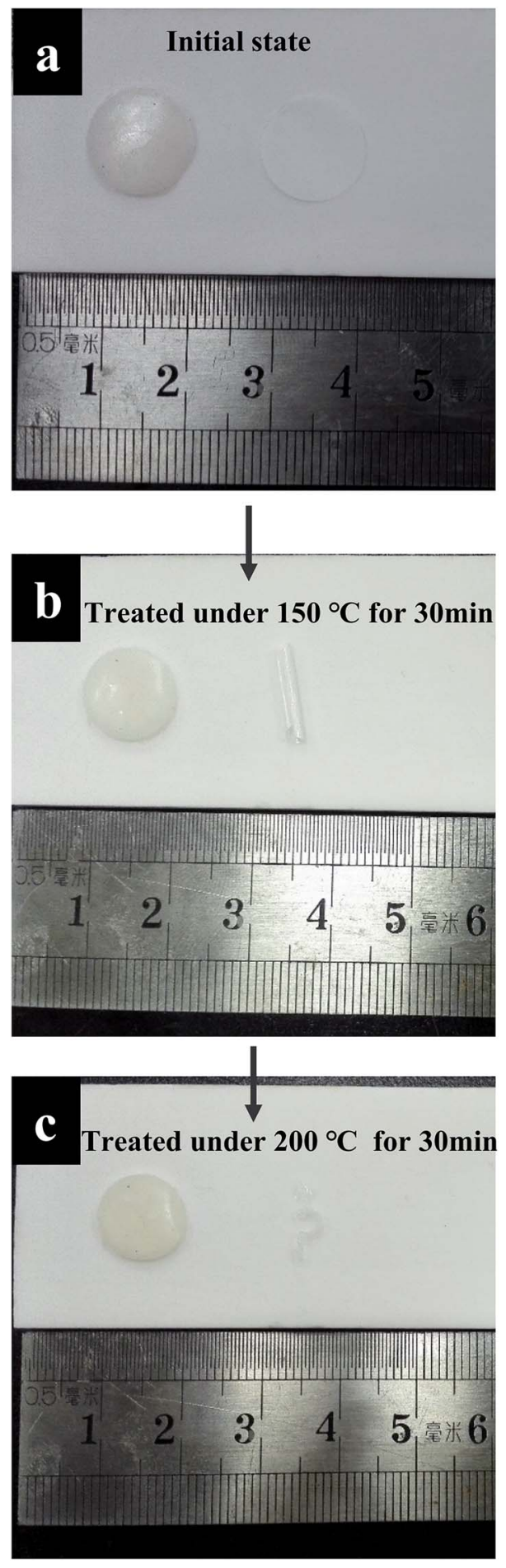

Fig. 2 Photo image of GPE and commercial separator (a) initial state, (b) heat treatment at $150{ }^{\circ} \mathrm{C}$ for $30 \mathrm{~min}$ and (c) further heat treatment at $200{ }^{\circ} \mathrm{C}$ for $30 \mathrm{~min}$. 
data of Table 1, it is clear that the ionic conductivity increases with the weight content of the liquid electrolyte. But the heat flow of the GPE calculated from DSC test shows a contrary tendency. For comparison, the that the amount of exothermic heat of pure liquid electrolyte heat is also tested by calculating from the heat flow of the DSC test, the value is $405 \mathrm{~J} \mathrm{~g}^{-1}$. Taking into account of all the factors, the composition of GPE-0 was chosen to be studied in this paper.

Thermal stability is one of the most important factors for the application of the polymer electrolyte. Good thermal stability can definitely enhance the safety property of the lithium ion battery. The thermal properties of the synthesized GPE were tested and presented in Fig. 2. The synthesized gel polymer electrolyte membrane and the commercialized Celgard separators were both heated in the air under the same temperature for same time. When heated at $150{ }^{\circ} \mathrm{C}$ for $30 \mathrm{~min}$ in air, the gel polymer electrolyte shows no different change, while the commercialized Celgard separators treated under the same conditions suffer from severe thermal shrinkage (Fig. 2b). Then the treated temperature was raised to $200{ }^{\circ} \mathrm{C}$ for another $30 \mathrm{~min}$. The gel polymer electrolyte maintained its original dimension, while the commercialized Celgard separator was almost burnt up (Fig. 2c). The shrinkage of the separator could cause severe internal shortcuts, which could lead to fire breakout or battery explosion. It's easy to tell that gel polymer electrolyte gained improved thermal stability than the commercialized separator, which is beneficial for the improvement of safety properties for lithium ion batteries. The thermogravimetric analysis (TGA) and differential scanning calorimetry (DSC) thermograms were shown in Fig. 4. From the DSC thermogram, it can be seen that the GPE start to decompose at $200{ }^{\circ} \mathrm{C}$. The weight loss of GPE from TGA before $200{ }^{\circ} \mathrm{C}$ can be ascribed to the evaporation of the liquid solvent. The GPE shows a better flame retarding ability which is an important factor for the enhancement of the safety property of the lithium ion battery. Most of the commercialized separators are combustible due to the component materials. The combustion test of the commercial separator and the gel polymer electrolyte membrane is performed in

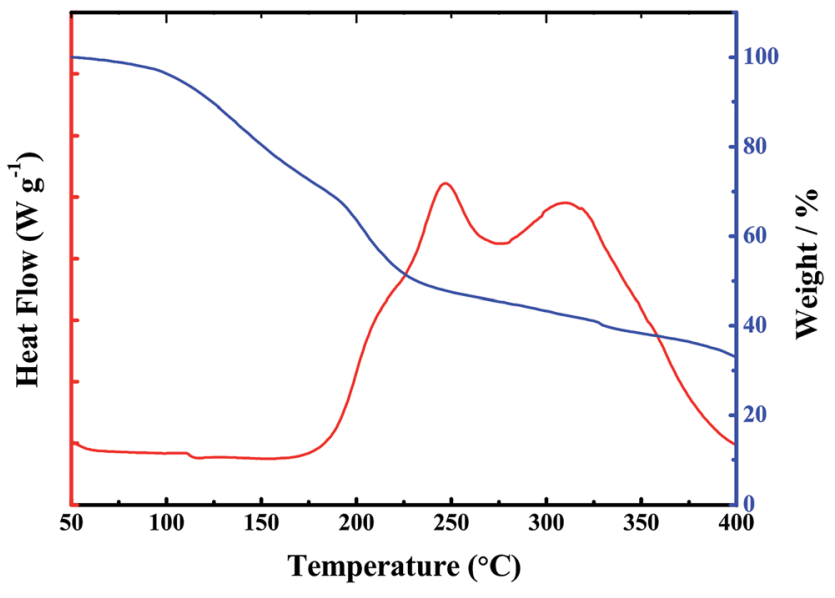

Fig. 4 Thermogravimetric analysis and Differential Scanning Calorimetry (DSC) curves of the gel polymer electrolyte.

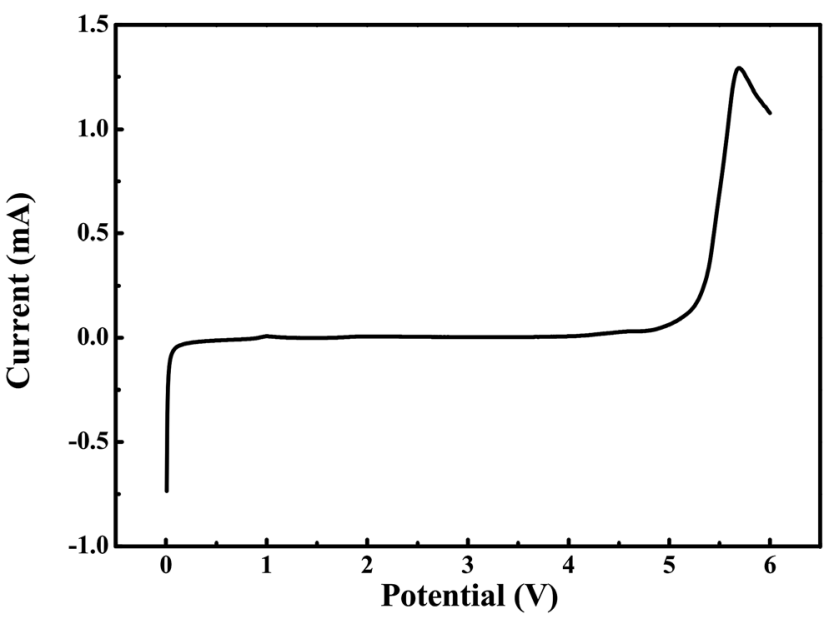

Fig. 5 Linear sweep voltammogram of the gel polymer electrolyte at $0.5 \mathrm{mV} \mathrm{s}^{-1}$.
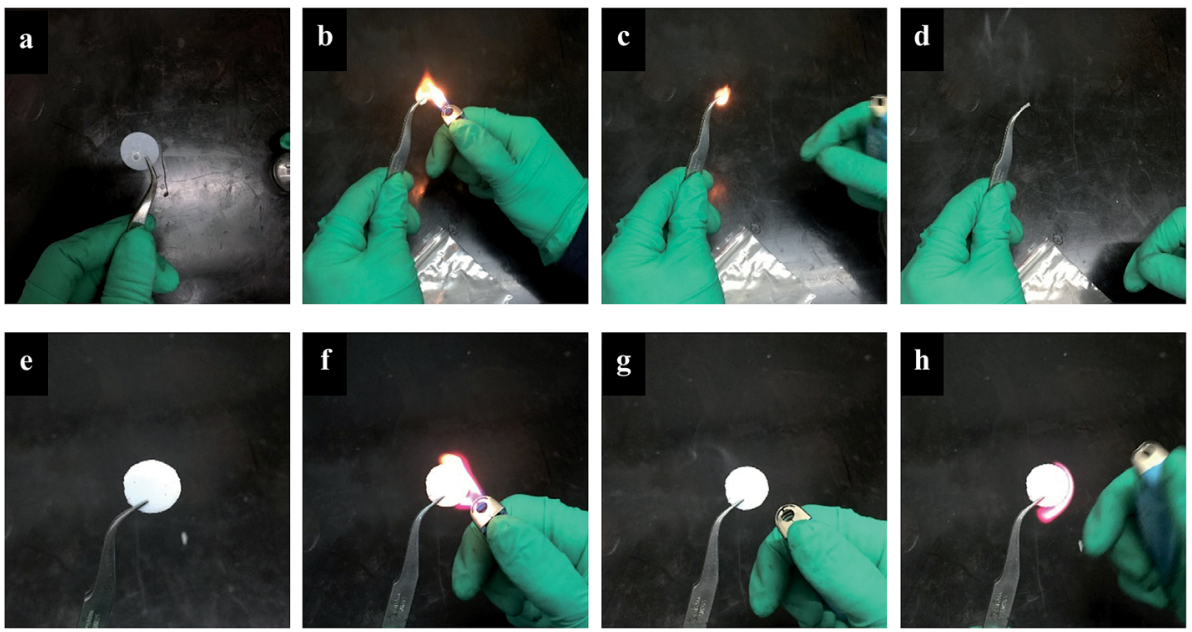

Fig. 3 The combustion test of the $(a-d)$ commercialized separator and $(e-h)$ gel polymer electrolyte membrane. 
this paper by setting both of the membranes on fire. When set on fire, the commercial separator shrank severely and on fire immediately. The separator saturated with the electrolyte was also set on fire, the absorbed liquid electrolyte was on fire immediately and the flame was very big. When the gel polymer electrolyte was set on fire, it was on fire after a relatively longer time and the dimension was unchanged during the process. The composite membrane shows better flame retarding ability (Fig. 3). This property also provides a higher safety performance for the composite membrane compared to the commercial separators.

The electrochemical window of the as-obtained gel polymer electrolyte were examined by linear-sweep voltammetry (LSV) with stainless steel as the working electrode and lithium metal as the reference and counter electrode (Fig. 5). The measurements were carried out in the potential range between 0 and $6.0 \mathrm{~V}\left(v s . \mathrm{Li} / \mathrm{Li}^{+}\right)$at a scan rate of $0.5 \mathrm{mV} \mathrm{s}^{-1}$ at room temperature. As presented in Fig. 4, no obvious significant oxidation current was observed until $4.9 \mathrm{~V}$, indicating that the obtained gel-polymer electrolyte samples were electrochemically stable up to $4.9 \mathrm{~V}$ ( $v s$. $\mathrm{Li} / \mathrm{Li}^{+}$), which is similar to that of the commercialized Celegard membrane soaked with liquid electrolyte because liquid electrolytes are the main composition of the gel polymer electrolyte. This wide electrochemical window is enough for lithium ion batterie.

The ionic conductivities of the composite gel-polymer electrolytes were examined by electrochemical impedance spectroscopy (EIS) with stainless-steel as blocking electrodes. The
EIS plot of the prepared GPE is shown in Fig. 5. There is a semicircle at high frequency area and a straight line at low frequency area, which corresponds to the EIS plots in other published literature. The ionic conductivity $(\sigma)$ of gel electrolyte was calculated using equation of $\sigma=l /(R \times A)$. The ionic conductivity of the gel polymer electrolyte at ambient temperature is $3.3 \times 10^{-3} \mathrm{~S} \mathrm{~cm}^{-1}$, which is comparable to the commercial liquid electrolyte with commercial separator of Celgard saturated with liquid electrolyte (Fig. S2 $\dagger$ ). This can be ascribed to the high uptake amount of the liquid electrolyte. These data clearly present that the ionic conductivity of the GPE is at the same level for the commercial separator, which is also satisfactory for practical lithium ion batteries. The ionic conductivity of the GPE at different temperature was tested. Fig. 6a shows the EIS plot of the Li/GPE/Li cell at temperatures from 30 to $60{ }^{\circ} \mathrm{C}$, from which the ionic conductivity of the GPE at different temperatures was obtained. The relationship of the lithium ion conductivity and temperature was shown in Fig. 6b. It can be seen that the ionic conductivity of the gel polymer electrolyte remains unchanged with the increasement of temperature and the activation energy is very low. As is known, it's better to have a uniform conductivity over a wide temperature range in order to make electrical devices applicable to a wide range of service temperatures. Hence the synthesized gel polymer electrolyte in this paper has a high conductivity and shows a promising application in electrical devices.

During charge-discharge cycling process of Li-ion batteries, anions such as $\mathrm{PF}_{6}{ }^{-}$in the electrolyte are also movable besides
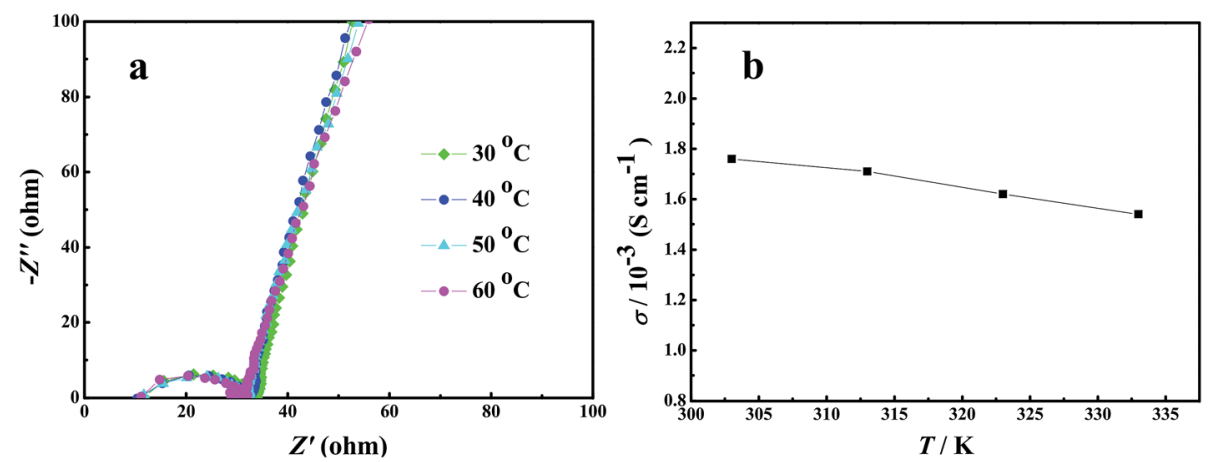

Fig. 6 (a) EIS plots of SS/GPE/SS at different temperatures and (b) ionic conductivity of the GPE at different temperatures.
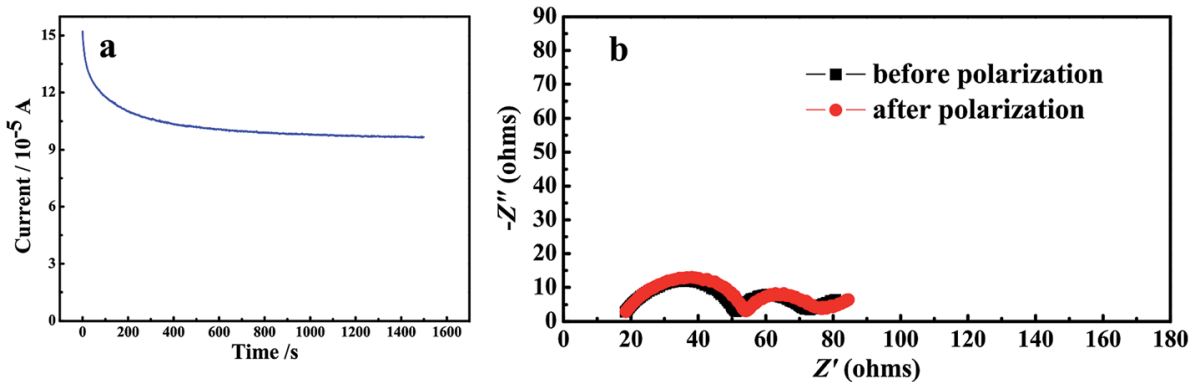

Fig. 7 (a) Chronoamperometry profiles for the GPE at $25^{\circ} \mathrm{C}$ in block cells using Li metal as both electrodes with step potential of $10 \mathrm{mV}$. (b) Nyquist profiles of the cell electrochemical impedance spectroscopy response before and after polarization. 
the transfer of lithium ion. Those anions will probably concentrate and be absorbed or decomposed on the surface of electrodes during the cycles, thus will affect the performance of the battery. Therefore, high lithium ion transference number will promote the performance of lithium ion batteries. Here, the lithium-ion transference number of the gel polymer electrolyte is estimated by chronoamperometry by using lithium as both work electrode and counter electrode. The selected impedance spectra and the time dependence response of DC polarization for the gel polymer electrolyte is shown in Fig. 7. The calculated $\mathrm{Li}^{+}$ion transference numbers by comparing the initial and final current value is 0.76 for the gel polymer electrolyte. That is a satisfactory value when compared to that reported in the literature and is suitable for future application of the GPE. The high lithium transference number of the gel membrane is probably attributed to the large amount of organic solvent trapped within the polymer matrix.

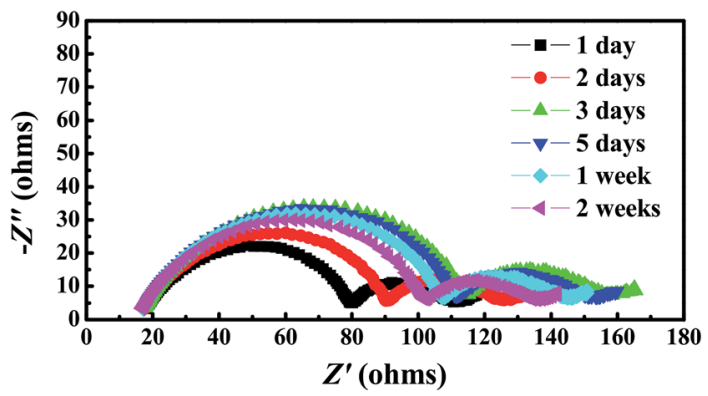

Fig. 8 Electrochemical impedance spectra (EIS) plots of the Li/GPE/Li cell in different time.
Chemical stability of the gel polymer electrolyte against metal $\mathrm{Li}$ is evaluated by monitoring the impedance of a $\mathrm{Li} / \mathrm{Li}$ symmetric cell during storage at room temperature. The gel polymer electrolyte was cut into pieces and sandwiched between two lithium foils. The impedance of the symmetric cell was monitored to character the chemical stability of the GPE. Some of the selected EIS spectra are displayed in Fig. 8. Initially, the impedance of the cell gradually increased with the storage time, reaching a maximum impedance value of $156 \Omega$, then decreased a little, finally stabilizes at around $135 \Omega$. This may be attributed to the formation of a solid electrolyte interphase (SEI) on the lithium surface. Upon time the SEI experiences a series of dissolution and re-formation steps, accounting for the stabilization of the impedance value. This can also been explained in other literature. ${ }^{34}$ The impedance value change is slightly during this process, which means the GPE shows an excellent chemical stability.

The electrochemical performance of the obtained gelpolymer electrolytes was evaluated in a solid-state battery using the synthesized GPE as both electrolyte and separator with CR2016 coin cell. $\mathrm{LiFePO}_{4}$ as the cathode and Li metal as the counter and reference electrode. The cells were cycled over a voltage range of 2.8-4.0 V. The cyclic voltammetry curve of the battery is presented in Fig. 9a. The oxidation peak is at $3.5 \mathrm{~V}$; the reduction peak is at $3.3 \mathrm{~V}\left(v s . \mathrm{Li}^{+} / \mathrm{Li}\right)$. The charge-discharge curve of the battery is shown in Fig. 9c. The charge-discharge profile shows a typical flat-shaped plateau at around $3.4-3.5 \mathrm{~V}$, and the voltage difference between charge and discharge curves is less than $0.2 \mathrm{~V}$, which are corresponds to the cyclic voltammetry test and consistent with $\mathrm{LiFePO}_{4}$ cathode tested in liquid
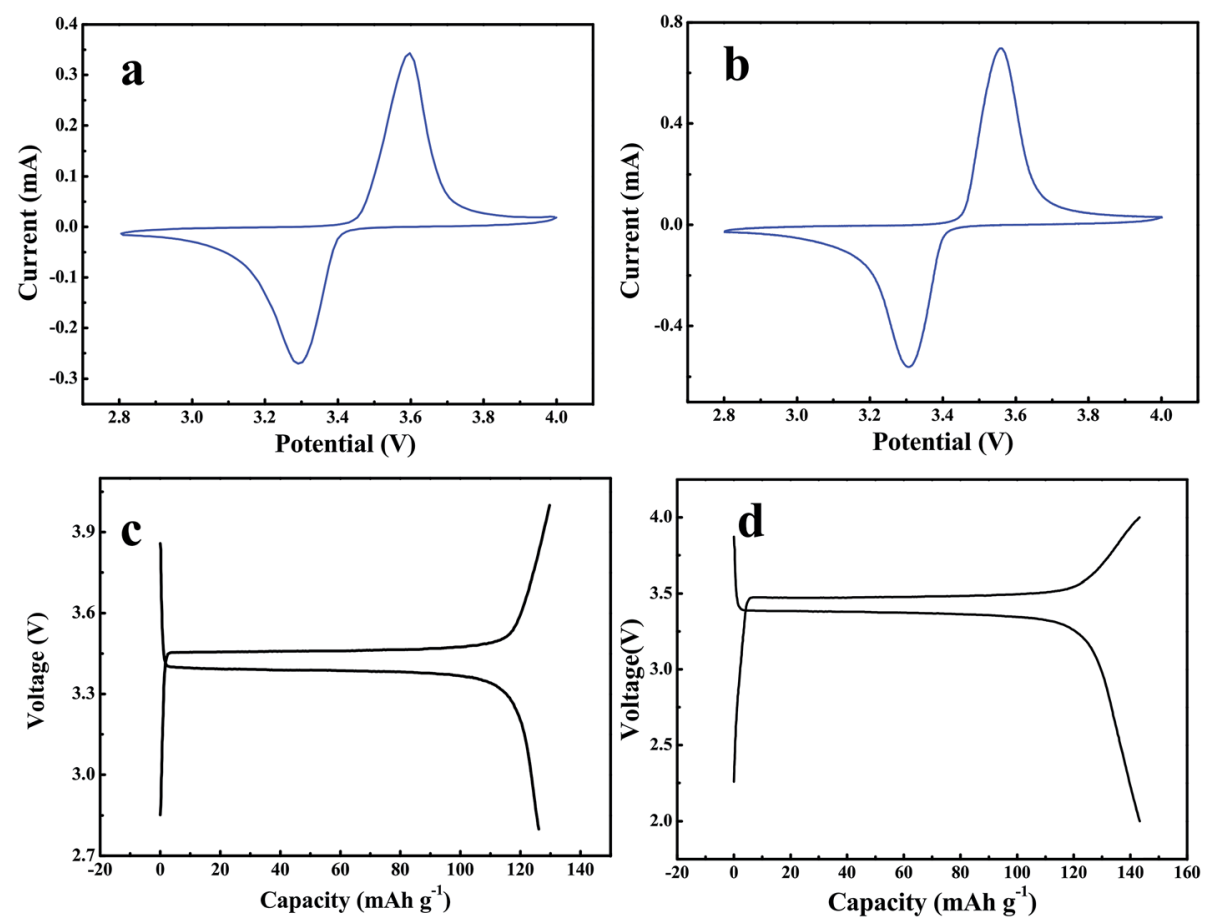

Fig. 9 (a) $\mathrm{CV}$ curve of $\mathrm{LiFePO}_{4}$ testing with GPE. (b) $\mathrm{CV}$ curve of $\mathrm{LiFePO}_{4}$ cathode with liquid electrolyte. (c) Charge-discharge curves of LiFePO 4 testing with GPE at $80 \mathrm{~mA} \mathrm{~g}^{-1}$. (d) Charge-discharge curves of $\mathrm{LiFePO}_{4}$ testing with liquid electrolyte at $80 \mathrm{~mA} \mathrm{~g}^{-1}$. 

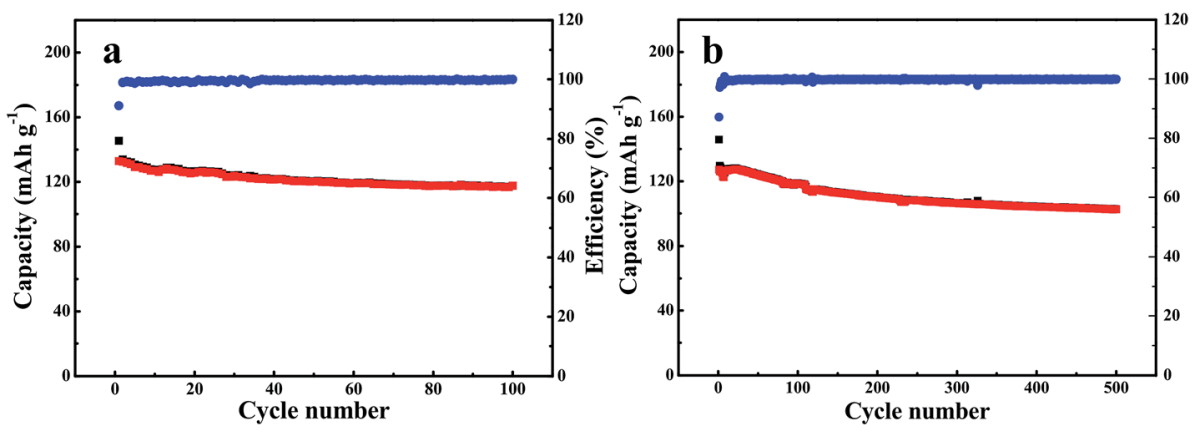

Fig. 10 Cycling performance of $\mathrm{LiFePO}_{4} / \mathrm{GPE} / \mathrm{Li}$ battery testing at current density of (a) $0.5 \mathrm{C}$, (b) $0.2 \mathrm{C}$.
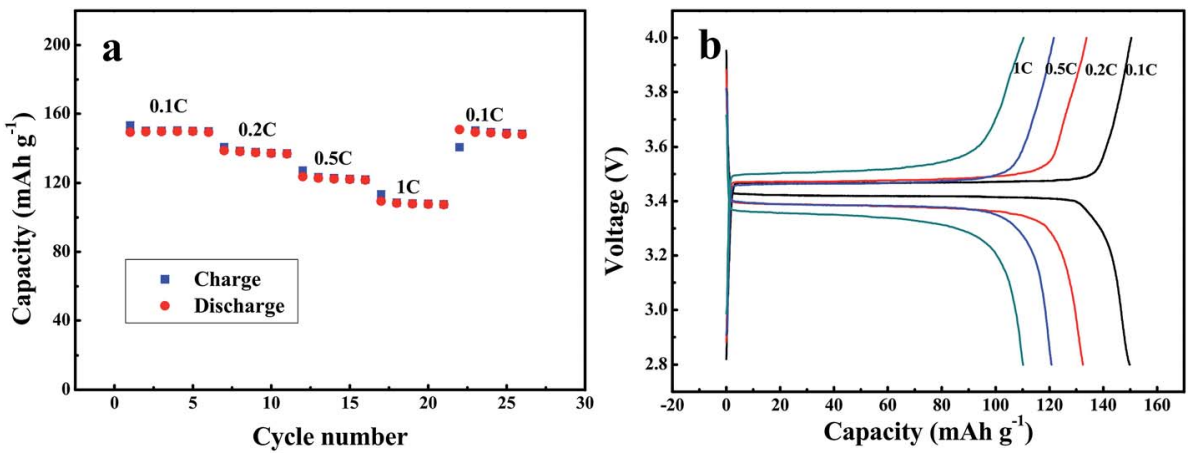

Fig. 11 (a) Charge-discharge curves of Li/GPE/LiFePO 4 at varying currents from $16 \mathrm{~mA} \mathrm{~g}^{-1}$ (0.1C) to $160 \mathrm{~mA} \mathrm{~g}^{-1}$ (1C). (b) Discharge capacities of $\mathrm{Li} / \mathrm{SPE} / \mathrm{AQ}$ at different currents.

electrolyte (Fig. 9b). The reversible capacity of the $\mathrm{LiFePO}_{4}$ at $0.5 \mathrm{C}$ for GPE is $133 \mathrm{~mA} \mathrm{~h} \mathrm{~g}^{-1}$ for (Fig. 9c).

The cycling behavior of $\mathrm{LiFePO}_{4}$ tested with gel polymer electrolyte was presented in Fig. 10. The battery was tested by charged and discharged between $2.8-4.0 \mathrm{~V}$ under a constant current density of $0.5 \mathrm{C}\left(1 \mathrm{C}=160 \mathrm{~mA} \mathrm{~g}^{-1}\right)$. During cycling process, there is no evident capacity fading. The discharge capacity of the cell using GPE is found to be $103 \mathrm{~mA} \mathrm{~h} \mathrm{~g}^{-1}$ after 500 cycles. The capacity retention is around $81 \%$, indicating that the gel polymer electrolyte membrane exhibits as a good cycling performance as to the commercial separator (Fig. S4†).

Fig. 11 shows the rate performances of $\mathrm{LiFePO}_{4}$ tested with the gel polymer electrolyte membrane. The battery was tested at various charge/discharge current densities from 0.1 to $1 \mathrm{C}$ with five cycles performed at each current density. When the cells were charged and discharged at $0.1 \mathrm{C}, 0.2 \mathrm{C}, 0.5 \mathrm{C}$ and $1 \mathrm{C}$, the discharge capacities of the $\mathrm{LiFePO}_{4}$ were 150, 139, 123 and $109 \mathrm{~mA} \mathrm{~h} \mathrm{~g}{ }^{-1}$ (Fig. 11). When the discharge current density went back to $0.5 \mathrm{C}$ at the end, the discharge capacity was almost recovered to the original value at the same rate for $130 \mathrm{~mA} \mathrm{~h} \mathrm{~g}^{-1}$. The discharge capacity of $\mathrm{LiFePO}_{4}$ tested with gel polymer electrolyte is similar with that tested with traditional liquid electrolyte under the same condition (Fig. S4†). The satisfactory rate capability of the gel polymer electrolyte is probably due to the higher ionic conductivity of the electrolyte.

\section{Conclusion}

In summary, a gel polymer electrolyte membrane consisting of PEO as the polymer matrix has been prepared and the performance of the GPE was characterized. The ionic conductivity of the gel polymer electrolyte is $3.3 \times 10^{-3} \mathrm{~S} \mathrm{~cm}^{-1}$ at room temperature, which is the same level of the commercial separator saturating with liquid electrolyte. The lithium ion transference number of the gel polymer membrane is as high as 0.76 , which is probably due to the high amount of the absorbed liquid electrolyte. The thermal stability of the GPE is improved a lot which will definitely improve the safety of lithium ion batteries. Meanwhile, the electrochemical performance of the gel membrane was evaluated by fabricating a battery using $\mathrm{LiFePO}_{4}$ as the cathode material and GPE as the electrolyte and separator. The battery shows an initial discharge capacity of $150 \mathrm{~mA} \mathrm{~h} \mathrm{~g}^{-1}$ at current density of $16 \mathrm{~mA} \mathrm{~g}^{-1}$ and $81 \%$ of capacity remained after 500 cycles of the charge-discharge process under 0.5C. And the rate capability is also very good when compared with that using commercial separator saturated with liquid electrolyte under the same condition. The GPE prepared here shows promising application ability in lithium ion batteries.

\section{Acknowledgements}

This work was partially supported by the National Natural Science Foundation of China (No. 21333002), the National Key Research and Development Plan (2016YFB0901503). 


\section{References}

1 J. B. Goodenough and J. M. Tarascon, nature, 2008, 451, 652657.

2 N.-S. Choi, Z. Chen, S. A. Freunberger, X. Ji, Y.-K. Sun, K. Amine, G. Yushin, L. F. Nazar, J. Cho and P. G. Bruce, Angew. Chem., Int. Ed., 2012, 51, 9994-10024.

3 B. Scrosati, J. Hassoun and Y.-K. Sun, Energy Environ. Sci., 2011, 4, 3287.

4 J. B. Goodenough and Y. Kim, J. Power Sources, 2011, 196, 6688-6694.

5 G. G. Eshetu, J.-P. Bertrand, A. Lecocq, S. Grugeon, S. Laruelle, M. Armand and G. Marlair, J. Power Sources, 2014, 269, 804-811.

6 A. S. Aricò, P. G. Bruce, B. Scrosati, J. M. Tarascon and W. v. Schalkwijk, Nat. Mater., 2005, 4, 366-377.

7 M. Nakayama, S. Wada, S. Kuroki and M. Nogami, Energy Environ. Sci., 2010, 3, 1995-2002.

8 J. Hassoun, P. Reale and B. Scrosati, J. Mater. Chem., 2007, 17, 3668.

9 W. Li, L. Chen, Y. Sun, C. Wang, Y. Wang and Y. Xia, Solid State Ionics, 2017, 300, 114-119.

$10 \mathrm{~J}$. Yi, X. Liu, S. Guo, K. Zhu, H. Xue and H. Zhou, ACS Appl. Mater. Interfaces, 2015, 7, 23798-23804.

11 K. Fu, Y. Gong, J. Dai, A. Gong, X. Han, Y. Yao, C. Wang, Y. Wang, Y. Chen, C. Yan, Y. Li, E. D. Wachsman and L. Hu, Proc. Natl. Acad. Sci. U. S. A., 2016, 113, 7094-7099.

12 S. Wu, J. Yi, K. Zhu, S. Bai, Y. Liu, Y. Qiao, M. Ishida and H. Zhou, Adv. Energy Mater., 2017, 7, 1601759.

13 J. Yi and H. Zhou, ChemSusChem, 2016, 9, 2391-2396.

14 J. Yi, S. Wu, S. Bai, Y. Liu, N. Li and H. Zhou, J. Mater. Chem. A, 2016, 4, 2403-2407.

15 S. S. Zhang and D. T. Tran, J. Mater. Chem. A, 2014, 2, 7383.

16 H. Zhong, C. Wang, Z. Xu, F. Ding and X. Liu, Sci. Rep., 2016, 6, 25484.

17 K. N. Jung, J. I. Lee, J. H. Jung, K. H. Shin and J. W. Lee, Chem. Commun., 2014, 50, 5458-5461.

18 L. Hu and Y. Cui, Energy Environ. Sci., 2012, 5, 6423.

19 M. Que, Y. Tong, G. Wei, K. Yuan, J. Wei, Y. Jiang, H. Zhu and Y. Chen, J. Mater. Chem. A, 2016, 4, 14132-14140.

20 C. Ma, J. Zhang, M. Xu, Q. Xia, J. Liu, S. Zhao, L. Chen, A. Pan, D. G. Ivey and W. Wei, J. Power Sources, 2016, 317, 103-111.
21 Y. Zhang, W. Cai, R. Rohan, M. Pan, Y. Liu, X. Liu, C. Li, Y. Sun and H. Cheng, J. Power Sources, 2016, 306, 152-161.

22 Y. Zhao, C. Wu, G. Peng, X. Chen, X. Yao, Y. Bai, F. Wu, S. Chen and X. Xu, J. Power Sources, 2016, 301, 47-53.

23 D. Zhou, Y.-B. He, R. Liu, M. Liu, H. Du, B. Li, Q. Cai, Q.-H. Yang and F. Kang, Adv. Energy Mater., 2015, 5, 1500353.

24 J. Zhang, L. Yue, P. Hu, Z. Liu, B. Qin, B. Zhang, Q. Wang, G. Ding, C. Zhang, X. Zhou, J. Yao, G. Cui and L. Chen, Sci. Rep., 2014, 4, 6272-6279.

25 A. Ngamaroonchote and C. Chotsuwan, J. Appl. Electrochem., 2016, 46, 575-582.

26 X. Luo, Y. Liao, H. Xie, Y. Zhou, Q. Huang and W. Li, Electrochim. Acta, 2016, 220, 47-56.

27 A. Manuel Stephan, Eur. Polym. J., 2006, 42, 21-42.

28 Y. Zhu, S. Xiao, Y. Shi, Y. Yang, Y. Hou and Y. Wu, Adv. Energy Mater., 2014, 4, 1300647.

29 Y. Zhu, F. Wang, L. Liu, S. Xiao, Z. Chang and Y. Wu, Energy Environ. Sci., 2013, 6, 618-624.

30 Y. Tominaga and M. Endo, Electrochim. Acta, 2013, 113, 361365.

31 C. V. Amanchukwu, H. H. Chang, M. Gauthier, S. Feng, T. P. Batcho and P. T. Hammond, Chem. Mater., 2016, 28, 7167-7177.

32 W. Yang, W. Yang, J. Feng, Z. Ma and G. Shao, Electrochim. Acta, 2016, 210, 71-78.

33 Y. Zhu, F. Wang, L. Liu, S. Xiao, Y. Yang and Y. Wu, Sci. Rep., 2013, 3, 3187.

34 C. Fasciani, S. Panero, J. Hassoun and B. Scrosati, J. Power Sources, 2015, 294, 180-186.

35 P. Hu, J. Zhao, T. Wang, C. Shang, J. Zhang, B. Qin, Z. Liu, J. Xiong and G. Cui, Electrochem. Commun., 2015, 61, 32-35.

36 H. Gao, B. Guo, J. Song, K. Park and J. B. Goodenough, Adv. Energy Mater., 2015, 5, 1402235.

37 Y. S. Zhu, S. Y. Xiao, M. X. Li, Z. Chang, F. X. Wang, J. Gao and Y. P. Wu, J. Power Sources, 2015, 288, 368-375.

38 H. Cheng, C. Zhu, B. Huang, M. Lu and Y. Yang, Electrochim. Acta, 2007, 52, 5789-5794.

39 Y. Tominaga, S. Asai, M. Sumita, S. Panero and B. Scrosati, J. Power Sources, 2005, 146, 402-406.

40 S. S. Jeong, Y. T. Lim, Y. J. Choi, G. B. Cho, K. W. Kim, H. J. Ahn and K. K. Cho, J. Power Sources, 2007, 174, 745-750. 